\title{
In Vivo Imaging of Cell Proliferation Enables the Detection of the Extent of Experimental Rheumatoid Arthritis by $3^{\prime}$-Deoxy-3'-18F-Fluorothymidine and Small-Animal PET
}

\author{
Kerstin Fuchs ${ }^{1,2}$, Ursula Kohlhofer ${ }^{3}$, Leticia Quintanilla-Martinez ${ }^{3}$, Denis Lamparter ${ }^{1}$, Ina Kötter ${ }^{4}$, Gerald Reischl ${ }^{1}$, \\ Martin Röcken ${ }^{2}$, Bernd J. Pichler ${ }^{1}$, and Manfred Kneilling ${ }^{2}$ \\ ${ }^{I}$ Laboratory for Preclinical Imaging and Imaging Technology of the Werner Siemens-Foundation, Department of Preclinical Imaging \\ and Radiopharmacy, Eberhard Karls University, Tübingen, Germany; ${ }^{2}$ Department of Dermatology, Eberhard Karls University, \\ Tübingen, Germany; ${ }^{3}$ Department for Pathology, Eberhard Karls University, Tübingen, Germany; and ${ }^{4}$ Department of Internal \\ Medicine II, Eberhard Karls University, Tübingen, Germany
}

The aim of this work was to study the feasibility of measuring cell proliferation noninvasively in vivo during different stages of experimental arthritis using the PET proliferation tracer $3^{\prime}$-deoxy-3'-18 F-fluorothymidine ( $\left.{ }^{18} \mathrm{~F}-\mathrm{FLT}\right)$. Methods: We injected mice with serum containing glucose-6-phosphate-isomerasespecific antibodies to induce experimental arthritis, and we injected control mice with control serum. Animals injected with ${ }^{18} \mathrm{~F}-\mathrm{FLT} 1,3,6$, and $8 \mathrm{~d}$ after the onset of disease were analyzed in vivo by PET, PET/CT, or PET/MR imaging followed by autoradiography analysis. The ${ }^{18} \mathrm{~F}-\mathrm{FLT}$ uptake in the ankles and forepaws was quantified on the basis of the PET images by drawing standardized regions of interest. To correlate the in vivo PET data with cell proliferation, we performed Ki-67 immunohistochemistry of diseased and healthy joints at the corresponding time points. Results: Analysis of the different stages of arthritic joint disease revealed enhanced ${ }^{18} \mathrm{~F}-\mathrm{FLT}$ uptake in arthritic ankles $(2.2 \pm 0.2$ percentage injected dose per gram [\%ID/g]) and forepaws $(2.1 \pm 0.3 \% \mathrm{ID} / \mathrm{g})$, compared with healthy ankles $(1.4 \pm 0.3$ $\% \mathrm{ID} / \mathrm{g}$ ) and forepaws ( $1.5 \pm 0.5 \% \mathrm{ID} / \mathrm{g})$, as early as $1 \mathrm{~d}$ after the glucose-6-phosphate-isomerase serum injection, a time point characterized by clear histologic signs of arthritis but only slight ankle swelling. The ${ }^{18} \mathrm{~F}-\mathrm{FLT}$ uptake in the ankles $(3.5 \pm 0.3 \%$ ID/ g) reached the maximum observed level at day 8 . Ki-67 immunohistochemical staining of the arthritic ankles and forepaws revealed a strong correlation with the in vivo ${ }^{18} \mathrm{~F}-\mathrm{FLT}$ PET data. $\mathrm{PET} / \mathrm{CT}$ and PET/MR imaging measurements enabled us to identify whether the ${ }^{18} \mathrm{~F}-\mathrm{FLT}$ uptake was located in the bone or the soft tissue. Conclusion: Noninvasive in vivo measurement of cell proliferation in experimental arthritis using ${ }^{18} \mathrm{~F}-\mathrm{FLT}$ PET is a promising tool to investigate the extent of arthritic joint inflammation.

\footnotetext{
Received Mar. 29, 2012; revision accepted Aug. 7, 2012.

For correspondence or reprints contact: Bernd J. Pichler, Laboratory for Preclinical Imaging and Imaging Technology of the Werner SiemensFoundation, Department of Preclinical Imaging and Radiopharmacy, Eberhard Karls University, Röntgenweg 13, 72076 Tübingen, Germany.

E-mail: bernd.pichler@med.uni-tuebingen.de

Published online Dec. 4, 2012.

COPYRIGHT @ 2013 by the Society of Nuclear Medicine and Molecular Imaging, Inc.
}

Key Words: rheumatoid arthritis; ${ }^{18} \mathrm{~F}-\mathrm{FLT}$; in vivo imaging; autoimmune disease; animal model

J Nucl Med 2013; 54:151-158

DOI: 10.2967/jnumed.112.106740

A pproximately $1 \%-2 \%$ of the world's population has rheumatoid arthritis (RA), an autoimmune disease characterized by systemic and erosive synovitis and joint destruction (1). Arthritic joints display massive infiltration by inflammatory cells, neovascularization, and expression of a wide range of proinflammatory mediators, ultimately resulting in pannus formation and subsequent cartilage and bone destruction $(2,3)$. Our earlier studies on glucose6-phosphate-isomerase (GPI) arthritis showed strongly enhanced integrin $\alpha_{v} \beta_{3}$ activity, as determined by ${ }^{18} \mathrm{~F}$ galacto-RGD PET, in the ankles of diseased mice (4).

Early treatment of RA patients with antiinflammatory drugs such as nonsteroidal antiphlogistics, steroids, methotrexate, or biologics is important for protecting against disease progression and joint destruction and is essential for achieving complete RA remission (5-7). Thus, early diagnosis of RA, before the onset of joint destruction, is of special importance. Noninvasive molecular imaging using dedicated, highly sensitive PET systems with high spatial resolution and with specific radiolabeled biomarkers is often better than conventional radiography, CT, MR imaging, power Doppler ultrasonography, and quantitative ultrasonography for identifying the extent of the disease (8-14).

Currently, the most commonly used PET tracer in oncology is ${ }^{18} \mathrm{~F}-\mathrm{FDG}$, a biomarker for glucose metabolism $(15,16)$. Only a few studies have focused on using ${ }^{18}$ F-FDG to detect inflammation and the effect of antiinflammatory drugs in patients $(17,18)$ or mice. Recently, Irmler et al. reported that ${ }^{18}$ F-FDG PET enables the early detection of metabolic changes in inflamed joints by allowing the measurement of 
glucose metabolism and enabling the study of disease progression over time in an experimental RA mouse model (19).

RA disease progression is accompanied by the proliferation of synoviocytes, primarily synovial fibroblasts and infiltrating inflammatory leukocytes (20). 3'-deoxy$3^{\prime}-{ }^{18} \mathrm{~F}$-fluorothymidine $\left({ }^{18} \mathrm{~F}\right.$-FLT) is a well-known and frequently used radiotracer for noninvasive in vivo analysis of cell proliferation in human and rodent cancers and is clinically used to validate the effects of therapeutic agents $(21-24) .{ }^{18} \mathrm{~F}-\mathrm{FLT}$ is transported into the cell by nucleoside transporters (25), phosphorylated by thymidine kinase 1 (tk-1) to form ${ }^{18}$ F-FLT monophosphate, and subsequently trapped within the cell $(26,27)$. Tk-1 is highly active, particularly between the late G1 and early G2 phases of the cell cycle $(28,29)$.

To our knowledge, only van Waarde et al. have investigated ${ }^{18} \mathrm{~F}-\mathrm{FLT}$ uptake in the context of inflammation, using an experimental model of sterile inflammation initiated by turpentine injection into muscles. However, no significant differences in tracer uptake could be detected between healthy and inflamed muscle tissues (30).

Interestingly, to date nobody besides us (31) has studied the use of noninvasive ${ }^{18} \mathrm{~F}$-FLT PET imaging as a tool to detect cell proliferation in arthritis or other autoimmune diseases in vivo.

Thus, the aim of this study was to investigate the feasibility of ${ }^{18}$ F-FLT PET imaging to quantify cell proliferation at different stages of GPI-induced arthritis, with the use of combined PET/MR imaging and PET/CT imaging to provide additional anatomic information. We examined ${ }^{18}$ F-FLT uptake during different stages of GPI-induced arthritis and its correlation with Ki-67 protein expression, an excellent immunohistochemical marker for proliferating cells, in histologic slices of arthritic ankles.

\section{MATERIALS AND METHODS}

\section{GPI-Induced Arthritis}

GPI serum was obtained from generation $1(\mathrm{~K} / \mathrm{BxN}$ mice $1-3$ mo old), and control serum was obtained from C57BL/6 mice 1-6 mo old. The GPI and control sera were pooled and diluted 1:1 (v/ v) with saline before injection. We injected $100 \mu \mathrm{L}$ of either GPI serum or control serum intraperitoneally into female BALB/c mice between 8 and 12 wk old (Charles River). Ankle thickness was measured with an Oditest micrometer (Kroeplin) before serum transfer and at the indicated time points after serum transfer. ${ }^{18} \mathrm{~F}$-FLT PET was performed on days $1,3,6$, and 8 after serum injection. The animal studies were conducted according to German Animal Protection Law protocols for animal use and care and were approved by the Regierungspräsidium Tübingen.

\section{PET Imaging}

High-resolution in vivo PET imaging was conducted using our Inveon small-animal PET scanner (Siemens Medical Solutions) (32). The spatial resolution in the reconstructed PET images was $1.4 \mathrm{~mm}$, the axial field of view was $12.7 \mathrm{~cm}$, and the transaxial field of view was $10 \mathrm{~cm} .{ }^{18} \mathrm{~F}$-FLT with an activity of $8.6 \pm 1.3 \mathrm{MBq}$ was injected in the tail vein of arthritic and healthy mice. Data were analyzed by drawing standardized regions of interest $3.5 \mathrm{~mm}$ in diameter. Three regions of interest were placed on 3 image slices, over the areas with maximum activity in the inflamed joints and, as a control, in the healthy joints. The images were analyzed using PMOD software (PMOD Technologies Ltd.), and overlays of the PET/MR (GPI, $n=2$; control, $n=2$ ) and PET/CT (GPI, $n=2$; control, $n=2$ ) images were realized with Inveon Research Workplace software (Siemens Healthcare). The list-mode data were reconstructed using iterative ordered-subset expectation maximization, corrected for decay, and normalized to the injected activity. The PET tracer uptake was reported as percentage injected dose (\%ID) per gram of tissue.

The scans consisted of either 20-min static PET scans initiated 30 min after tracer injection or dynamic PET scans beginning at the time of ${ }^{18} \mathrm{~F}-\mathrm{FLT}$ injection and continuing for $90 \mathrm{~min}$. The dynamic data were divided into 15 time frames to construct timeactivity curves. Imaging was performed at day 1 (GPI, $n=2$; control, $n=1$ ), day 3 (GPI, $n=2$; control, $n=1$ ), day 6 (GPI, $n=2$; control, $n=2$ ), and day 8 (GPI, $n=1$; control, $n=1$ ) after serum transfer. The mice were anesthetized using $1.5 \mathrm{vol} \%$ isoflurane vaporized in $100 \%$ oxygen $(1.5 \mathrm{~L} / \mathrm{min})$ and warmed during PET scanning and tracer uptake.

CT

Small-animal CT scans were performed using a combined highresolution SPECT/CT scanner (Inveon; Siemens Healthcare) using $80 \mathrm{kVp} \mathrm{x}$-rays at a current of $500 \mathrm{~mA}$. The animals were anesthetized using 1.5 vol\% isoflurane vaporized in $100 \%$ medical oxygen, and their respiration was monitored. The exposure time per projection was $250 \mathrm{~ms}$, and a binning factor of 4 was used, resulting in a reconstructed pixel size of $104 \mu \mathrm{m}$. Planar images were acquired from 400 projections over $200^{\circ}$ of rotation in step-and-shoot mode. The images were reconstructed using a cone-beam filtered backprojection algorithm.

\section{MR Imaging}

MR imaging was performed using a 7-T small-animal scanner (ClinScan; Bruker Biospin MRI GmbH). The animals were anesthetized using $1.5 \mathrm{vol} \%$ isoflurane vaporized in $100 \%$ medical oxygen, and their respiration was monitored and used to trigger MR imaging acquisition (model 1030; SAI Inc.). Imaging was performed using a T2-weighted 3-dimensional turbo spin echo sequence (echo time/repetition time, 205/3,000 ms; field of view, $35 \times 57 \mathrm{~mm}^{2}$; matrix, $160 \times 256$; slice thickness, $0.22 \mathrm{~mm}$; flip angle, $120^{\circ}$ ).

\section{Statistical Data Analysis}

All results were calculated as the mean values of the arthritic or healthy ankles \pm SD. The 2-tailed Student $t$ test was used to analyze differences between ${ }^{18}$ F-FLT uptake $(\% \mathrm{ID} / \mathrm{g})$ in the arthritic and healthy ankles in static and dynamic PET images using JMP statistical software (version 9; SAS Institute Inc.). $P$ values of less than 0.05 were considered to be statistically significant.

\section{Histologic Analysis, Radiopharmaceutical, and Autoradiography}

Please refer to the supplemental material (available online at http://jnm.snmjournals.org) for detailed data about the groups.

\section{RESULTS}

\section{Extent of Inflammation-Induced Cell Proliferation}

Figure 1A illustrates the course of ankle swelling during GPI-induced arthritis until day 13 after the GPI or control 


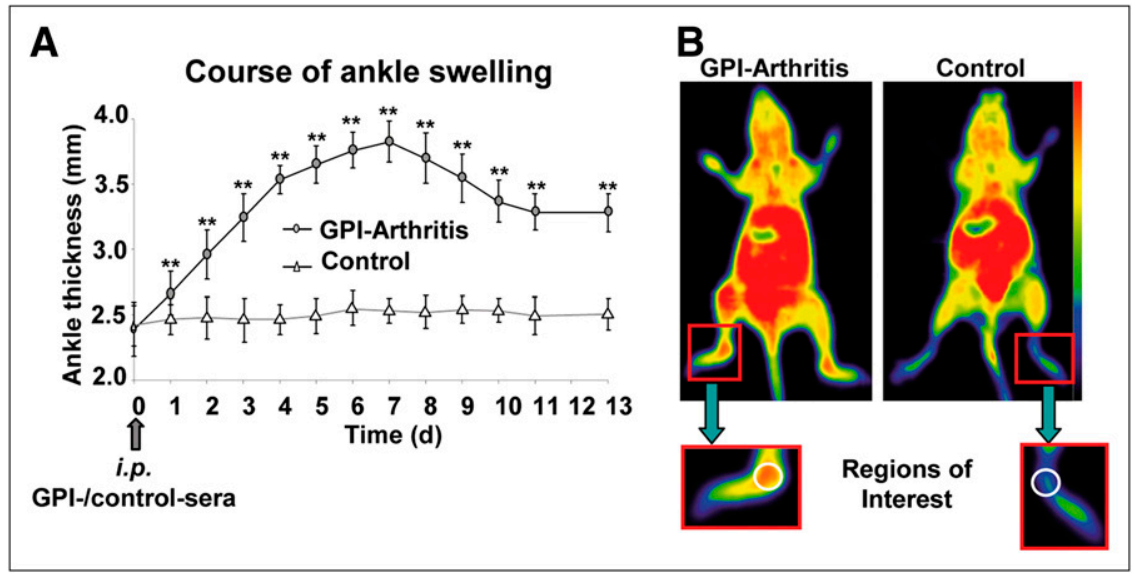

FIGURE 1. Representative course of ankle thickening after GPI or control serum transfer. (A) Ankle thickness was measured daily for $13 \mathrm{~d}$ after onset of disease. Maximum ankle thickness was observed between days 5 and 8 (GPI, $n=11$; control, $n=7$ ). (B) Representative ${ }^{18} \mathrm{~F}-\mathrm{FLT}$ PET images from arthritic and healthy control mouse on day 6 after GPI or control serum transfer indicating strongly enhanced ${ }^{18} \mathrm{~F}$-FLT uptake in arthritic ankles (left) compared with healthy ankles (right). Magnified areas of arthritic and healthy ankles are indicated by squares. Circles in magnified images indicate regions of interest drawn for quantitative analysis of ${ }^{18} \mathrm{~F}-\mathrm{FLT}$ uptake in vivo. $P$ values of $<0.05$ were considered to be statistically significant. $i . p$. $=$ intraperitoneal injection.

serum injection. In this study, slight ankle swelling was measurable as early as $24 \mathrm{~h}$ after the onset of arthritis, and the maximum ankle swelling was observed between days 5 and 8 after the onset of GPI-induced arthritis. The ankles of mice injected with the control serum displayed no signs of joint swelling or inflammation over the entire observation period (Fig. 1A). Representative ${ }^{18}$ F-FLT PET images on day 6 after the GPI serum transfer, a time point characterized by maximum ankle swelling and severe joint inflammation, displayed an impressive ${ }^{18} \mathrm{~F}$-FLT uptake in the ankles and in the front and back paws (Fig. 1B).

First, we asked whether noninvasive in vivo ${ }^{18} \mathrm{~F}$-FLT PET could detect early arthritis before joint inflammation is clinically visible. Thus, we conducted $90 \mathrm{~min}$ of dynamic PET measurements to analyze the kinetics of ${ }^{18} \mathrm{~F}-\mathrm{FLT}$ accumulation in both arthritic and healthy ankles. Represen- tative decay-corrected time-activity curves of arthritic and healthy ankles $1,3,6$, and $8 \mathrm{~d}$ after GPI or control serum injection are displayed in Figure 2A. Analysis of the ${ }^{18} \mathrm{~F}-$ FLT uptake kinetics $24 \mathrm{~h}$ after injection of the GPI serum, a time point with only slight ankle swelling (Supplemental Fig. 1A), yielded a 2-fold enhancement of tracer accumulation in arthritic ankles compared with healthy ankles. Beginning $3 \mathrm{~d}$ after the GPI serum injection, we observed an early peak of tracer uptake in arthritic ankles 5 min after the ${ }^{18}$ F-FLT injection (4-fold at day 3 and 7-fold at day 8 , compared with the control level), most likely caused by increased vascularization in the inflamed joints, resulting in increased blood flow. This peak was followed by a gradual decrease until the end of the experiment at $90 \mathrm{~min}$. Importantly, $90 \mathrm{~min}$ after the ${ }^{18} \mathrm{~F}-\mathrm{FLT}$ injection, tracer uptake in the GPI arthritic ankles (at days 3, 6, and 8)

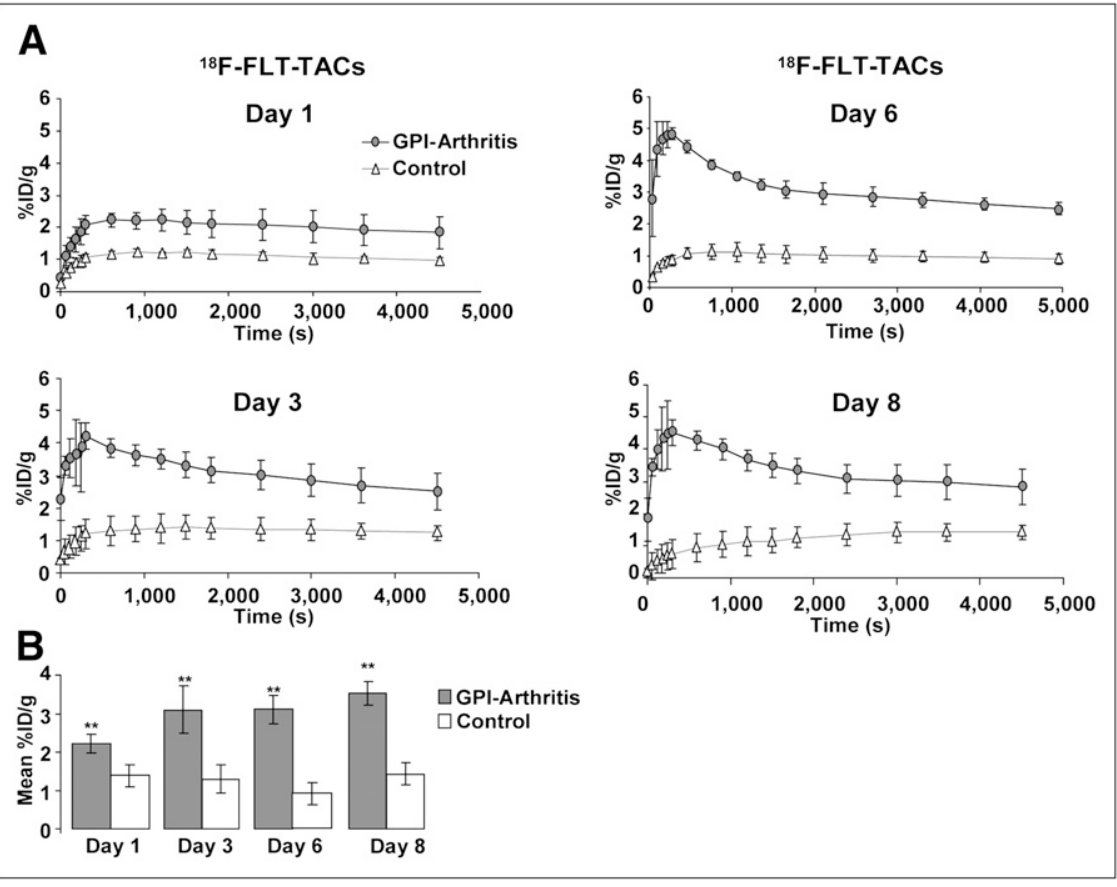

FIGURE 2. ${ }^{18} \mathrm{~F}-\mathrm{FLT}$ tracer uptake in arthritic and healthy ankles. (A) $90-$ min ${ }^{18} \mathrm{~F}$ FLT time-activity curves on days 1, 3, 6, and 8 after GPI or control serum injection. (B) Quantification of pooled dynamic and static ${ }^{18} \mathrm{~F}$-FLT PET scans in arthritic and healthy ankles indicated as mean $\% \mathrm{ID} / \mathrm{g}$ at days $1,3,6$, and 8 after serum transfer. ${ }^{18} \mathrm{~F}-\mathrm{FLT}$ uptake values denoted increased accumulation in arthritic joints after GPI serum ( $n=5-7$ ) injection, reaching maximum on day 8 , indicating enhanced cell proliferation. Healthy ankles $(n=3-6)$ of control serum-injected littermates exhibited constant ${ }^{18} \mathrm{~F}-\mathrm{FLT}$ tracer uptake at all corresponding time points. $P$ values of $<0.05$ were considered to be statistically significant. 
remained 2-fold higher than that observed in the healthy ankles (Fig. 2A). At days 1, 3, 6, and 8 after the control serum injection, tracer uptake in the healthy ankles remained at the same low level over the entire scanning time and displayed no injection peak (Fig. 2A).

The \%ID of ${ }^{18} \mathrm{~F}-\mathrm{FLT}$ in the arthritic ankles obtained from the static and dynamic PET scans was $2.2 \pm 0.2$ on day $1(n=7), 3.1 \pm 0.6$ on day $3(n=7), 3.1 \pm 0.4$ on day $6(n=5)$, and $3.5 \pm 0.3$ on day $8(n=7)$, whereas ${ }^{18}$ F-FLT uptake in the healthy joints was between $0.7 \pm 0.1$ and $1.4 \pm 0.3(n=3-6)$ on the indicated days (Fig. 2B). At day 8 after the GPI arthritis induction, we detected the highest level of ${ }^{18}$ F-FLT uptake in the arthritic ankles, although ankle swelling was less on day 8 than on day 6 (Fig. 2B and Supplemental Fig. 1A). The arthritic ankleto-healthy ankle ratio on day 1 was 1.6 ; the ratio on day 6 was 3.5 (Supplemental Fig. 2A). The enhanced in vivo ${ }^{18} \mathrm{~F}-$ FLT uptake after the onset of arthritic joint disease correlated well with the ankle swelling at days 1, 3, and 8 after the GPI serum transfer (Supplemental Fig. 2B). As in the human disease, GPI-induced arthritis progressed from the distal to the proximal joints. Thus, we measured higher ${ }^{18} \mathrm{~F}-$ FLT uptake on day 3 than on day 8 after GPI arthritis induction in the joints of the forepaws (Supplemental Fig. 3A). Ex vivo autoradiography analysis of the arthritic and healthy ankles $1,3,6$, and $8 \mathrm{~d}$ after the GPI serum or control serum injection indicated a strong correlation with the in vivo ${ }^{18} \mathrm{~F}-\mathrm{FLT}$ PET images (Supplemental Fig. 4).

\section{Measurements to Identify Exact Sites of Enhanced Cell Proliferation}

We conducted combined PET/CT and PET/MR imaging investigations of arthritic and healthy mice because this combined approach offers the capability of high-resolution 3-dimensional imaging with temporal and spatial information about ${ }^{18} \mathrm{~F}$-FLT biodistribution in arthritic and healthy ankles. Noninvasive in vivo MR imaging provides detailed anatomic information with high soft-tissue contrast of the synovial cartilage (33), whereas noninvasive in vivo CT reveals the bone structure. PET/CT (Fig. 3A) and PET/ MR imaging (Fig. 4A) measurements of healthy mice displayed enhanced ${ }^{18} \mathrm{~F}$-FLT accumulation in the bladder, intestine, and kidneys (Fig. 1B).

MR imaging indicated progressive ankle swelling and advanced accumulation of synovial fluid in the arthritic ankles, beginning at day 3 after the GPI serum injection, a typical sign of RA (Figs. 4B-4D).

The ${ }^{18}$ F-FLT PET images of the arthritic ankles $1 \mathrm{~d}$ after the GPI serum injection showed a homogeneous enhanced signal, compared with the healthy ankles (Figs. 3A, 3B, 4A, and $4 \mathrm{~B}$ ). Beginning $3 \mathrm{~d}$ after the GPI arthritis induction, we identified areas of enhanced ${ }^{18} \mathrm{~F}$-FLT uptake, indicating cell proliferation within the arthritic ankles (Figs. 3C and 4C). The number of areas of enhanced ${ }^{18} \mathrm{~F}$-FLT accumulation within the ankles increased further $8 \mathrm{~d}$ after the onset of GPI-induced arthritis (Figs. 3D and 4D).

${ }^{18} \mathrm{~F}-\mathrm{FLT}$ PET/CT overlays indicated that the greatest tracer uptake in the arthritic mice occurred proximal to the subtalar joints, without signs of bone destruction detected by CT or MR imaging even $8 \mathrm{~d}$ after the GPI serum injection (Figs. 3B-3D). Histologic analysis of the arthritic ankles obtained after the final ${ }^{18} \mathrm{~F}$-FLT PET/CT or ${ }^{18} \mathrm{~F}$-FLT PET/MR imaging studies revealed pannus formation and bone cortical erosion, the earliest phase of bone destruction, at the site of tendon insertion (Supplemental Fig. 5). Additionally, strong reactive periosteal
FIGURE 3. Localization of exact sites of ${ }^{18} \mathrm{~F}-\mathrm{FLT}$ accumulation in arthritic ankles (tibiocalcaneus joint) and control ankles by PET/CT. High-resolution CT provided detailed information about skeletal elements for accurate localization of ${ }^{18} \mathrm{~F}$-FLT $\mathrm{PET}$ signaling. Coronal and transversal images of ankles from CT (left), ${ }^{18} \mathrm{~F}-\mathrm{FLT}$ PET (middle), and coregistered ${ }^{18} \mathrm{~F}-\mathrm{FLT}$ PET/CT (right) images are shown. (A) Representative healthy mouse after control serum injection. (B-D) Representative arthritic mouse on days 1 (B), 3 (C), and 8 (D) after GPI serum injection. Increasing ${ }^{18} \mathrm{~F}-\mathrm{FLT}$ uptake in joints was observed by day 1 after arthritis induction. Further increases were observed until day 8 and were mainly in subtalar joints around bone. Circles in coronal images indicate transversal cutting planes.

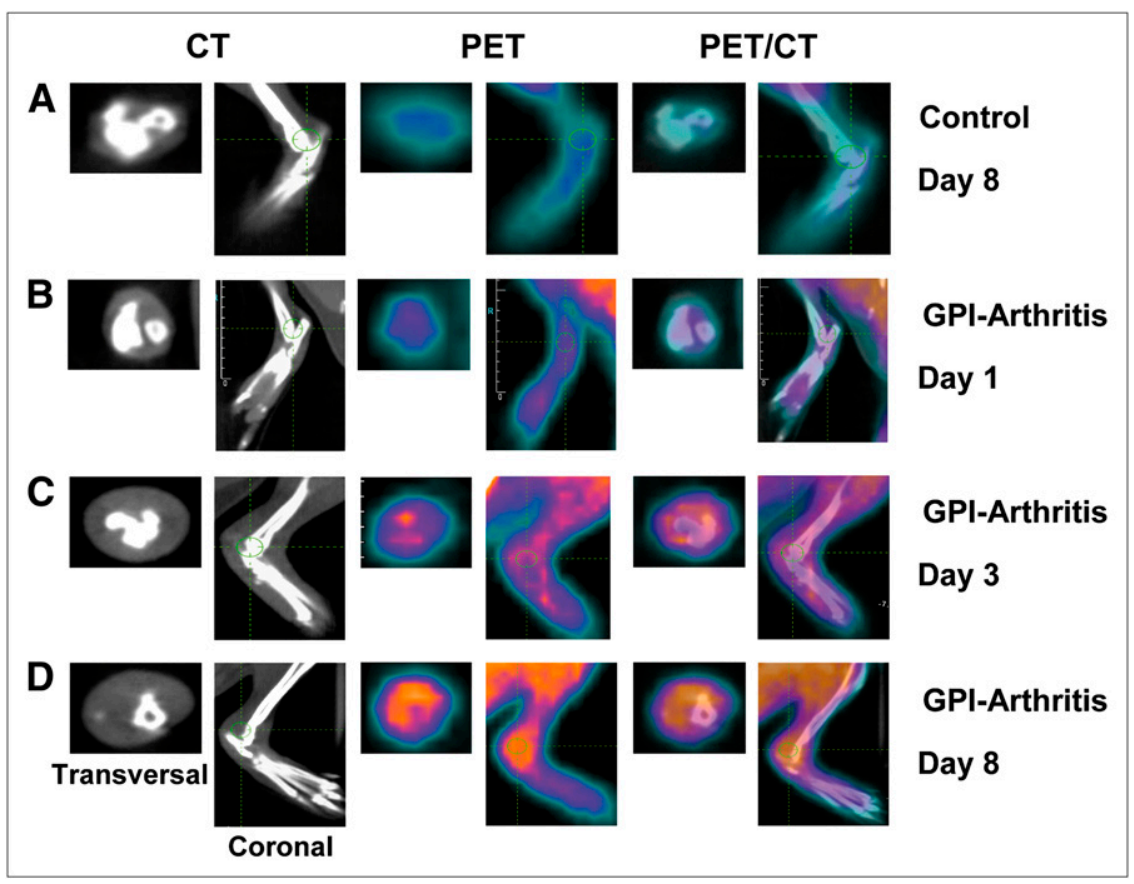




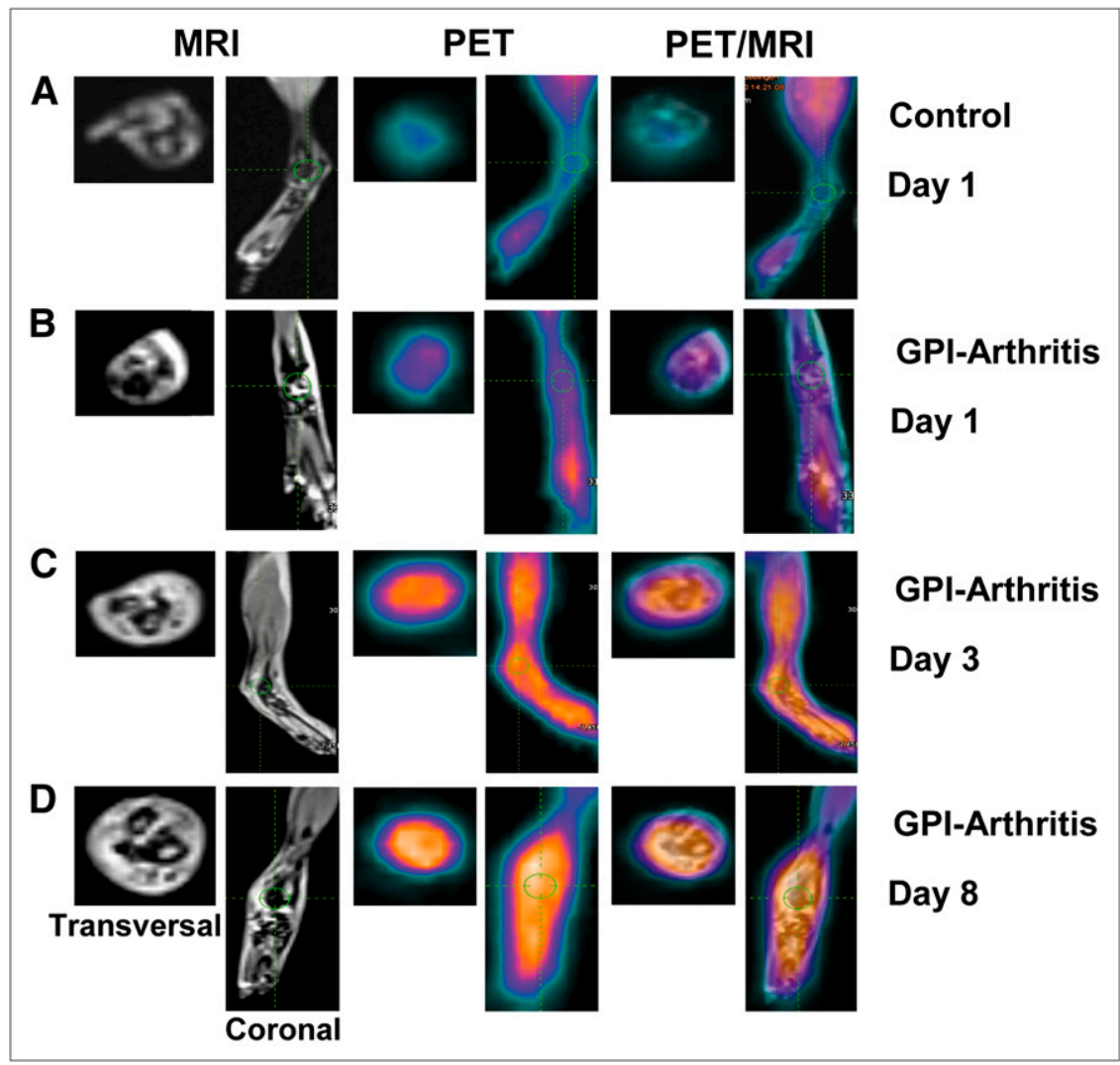

FIGURE 4. Localization of exact sites of ${ }^{18} \mathrm{~F}-\mathrm{FLT}$ accumulation in arthritic ankles (tibiocalcaneus joint) and control ankles by PET/MR imaging (MRI). Highresolution MR imaging provided detailed soft-tissue information for accurate localization of ${ }^{18} \mathrm{~F}$-FLT PET signaling. Coronal and transversal images of ankles from MR imaging (left), ${ }^{18} \mathrm{~F}-\mathrm{FLT}$ PET (middle), and coregistered ${ }^{18} \mathrm{~F}-\mathrm{FLT}$ PET/MR imaging (right) are shown. (A) Representative healthy mouse after control serum injection. (B-D) Representative GPI serum-injected mouse on days 1 (B), 3 (C), and 8 (D) after arthritis induction. ${ }^{18} \mathrm{~F}-\mathrm{FLT}$ uptake increased mainly in arthritic ankles between days 1 and 8 , indicating regions of high cell proliferation. MR scans showed increasing "white areas" around subtalar joints, indicating enrichment of synovial fluid, beginning on day 3 after onset of arthritic joint disease. Circles in coronal images indicate transversal cutting planes.

bone formation but no severe bone destruction was observed (Supplemental Fig. 5).

\section{Histopathologic Evaluation at Different Phases of Joint Inflammation}

Twenty-four hours after the GPI serum injection, the experimental mice that had been used for Ki-67 immunohistochemical analysis developed minor ankle swelling (Supplemental Fig. 1B). Hematoxylin and eosin staining of the arthritic ankles showed minor signs of inflammation localized to the synovia and to perisynovial soft tissue that had been infiltrated by a few inflammatory cells; however, the adipose tissue was preserved (Fig. 5, left and center panels). Three days after the onset of arthritis, the synovial membrane contained increased amounts of inflammatory cells, predominantly neutrophil granulocytes. The synovial membranes thickened and signs of fibrosis were visible, with increased vascularization and reduction of the synovial spaces. Analysis on day 8 after the GPI serum transfer showed a dense inflammatory infiltration in the synovium and in the subsynovial pericapsular tissue. The pericapsular tissue displayed a striking increase of fibrous connective tissue and pannus formation. The inflammation extended to the subcutaneous adipose tissue in several mice. The ankles showed the greatest numbers of inflammatory cells, and the synovial membranes covered the articular surfaces of the joints. In several cases, the synovial space was filled with fibrin and inflammatory cells. Additionally, erosion of the cortical bone, the earliest phase of bone destruction, at the site of the tendon insertion was observed. Interestingly, the bone near the joint revealed strong, reactive periosteal bone formation (Supplemental Fig. 5). Histologically, the ankles of the control serum-injected littermates showed normal joint structures with intact joint spaces between the synovium and the articular cartilage (Fig. 5, top row, left and center panels).

Ki-67 immunohistochemical staining of the healthy ankles 1-8 d after the control serum transfer showed that approximately $0 \%-5 \%$ of the cells stained positively. On day 1 after the GPI serum injection, an increased number of Ki-67-positive cells were already detectable, although there was no significant ankle swelling and only slight histopathologic signs of joint inflammation on day 1 (Fig. 5, right panel, and Supplemental Fig. 1B). On day 3 after the onset of GPIinduced arthritis, a further increase in Ki-67-positive cells was observed. At day 8, a time point at which severe ankle swelling and joint inflammation were observed, approximately $32 \% \pm$ $18 \%$ of the infiltrating inflammatory cells and local cells stained positively for Ki-67 (forepaws, $26 \% \pm 9 \%$; Supplemental Fig. 3B). The number of Ki-67-positive cells in the arthritic ankles correlated with the number of inflammatory cells and with the corresponding in vivo ${ }^{18} \mathrm{~F}$-FLT PET results. We were thus able to confirm our noninvasive in vivo ${ }^{18} \mathrm{~F}-\mathrm{FLT}$ PET measurements of cell proliferation using Ki-67 immunohistochemistry, further supporting the enhanced cellular proliferation rate in arthritic joints. 


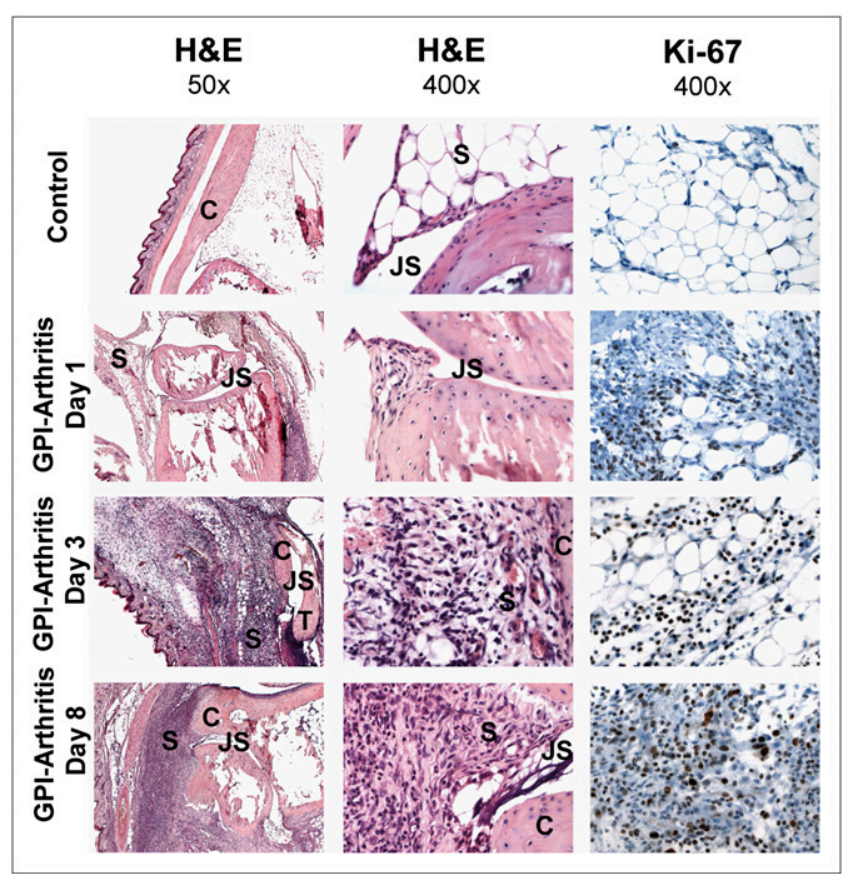

FIGURE 5. Hematoxylin- and eosin-stained slides from GPI-arthritic ankles on days 1,3 , and 8 after GPI serum transfer are shown at magnifications of $\times 50$ and $\times 400$. Increasing accumulation of inflammatory cells, predominately neutrophils; ongoing pannus formation; and joint destruction are evident. Hematoxylin- and eosinstained slides from healthy ankles of control serum-injected mice revealed no signs of inflammation (left and middle panels). Ki-67 staining $(\times 400)$ demonstrated an increasing number of highly proliferating cells between days 1 and 8 after arthritis induction. Control ankles showed few Ki-67-positive cells (right panels). $\mathrm{C}=$ cartilage; $\mathrm{JS}=$ joint space; $\mathrm{M}=$ muscle; $\mathrm{S}=$ synovium; $\mathrm{T}=$ tendon .

\section{DISCUSSION}

In this study we focused on the feasibility of using ${ }^{18} \mathrm{~F}-$ FLT PET to detect inflammation-induced cell proliferation and diagnose early arthritic joint inflammation in vivo using a GPI serum-transfer arthritis model that progresses as in humans from the distal to the proximal joints. GPI seruminduced arthritis is similar to human RA in being dependent on autoantibodies, which are responsible for disease development and progression $(34,35)$. By analyzing GPI-induced arthritis, we detected inflammation-induced cell proliferation on the first day after the onset of arthritis, a time point characterized by almost normal ankle thickness and no morphologic changes detectable by MR imaging. The ${ }^{18} \mathrm{~F}$-FLT uptake increased proportionally to the severity of the disease (Fig. 2B) and correlated well with ankle swelling (Supplemental Fig. 2B).

Kinetic analysis of ${ }^{18} \mathrm{~F}$-FLT uptake in the arthritic ankles showed an initial peak that started at day 3 after the GPI serum injection and was likely caused by enhanced perfusion in the inflamed ankles because of vasodilatation, increased blood flow, and blood vessel renewal. This analysis is consistent with earlier work that focused on angiogenesis in a GPI-induced arthritis mouse model (4). The initial peak appeared in the dynamic PET curves using other tracers (e.g., ${ }^{18} \mathrm{~F}-\mathrm{FDG},{ }^{18} \mathrm{~F}-\mathrm{FMISO}$, and ${ }^{18} \mathrm{~F}-\mathrm{FAZA}$ [unpublished data]), but the peak was absent in the ankles of arthritic mice $1 \mathrm{~d}$ after disease induction and in the control serum-injected healthy mice. To avoid a major influence of perfusion, static PET scans were started $30 \mathrm{~min}$ after the tracer injection.

To further rule out a dominant perfusion effect, we correlated ${ }^{18} \mathrm{~F}$-FLT data with the Ki-67 protein expression level, further confirming the specificity of the acquired in vivo data. Ki-67 is an excellent immunohistochemical marker for proliferating cells and is exclusively present during all active phases of the cell cycle (G(1), S, G(2), and mitosis) but not in resting cells $(\mathrm{G}(0))(36)$. Keen et al. reported a strong correlation between ${ }^{18} \mathrm{~F}-\mathrm{FLT}$ uptake, tk-1 expression, and Ki-67 expression in a human xenograft carcinoma model (29), but the relationship between tk- 1 and Ki-67 expression is not evident in every carcinoma model, as Ki-67 represents a somewhat larger amount of the cell cycle than tk-1 (29). Brockenbrough et al. recently suggested that the ${ }^{18} \mathrm{~F}-\mathrm{FLT}$ uptake may also be influenced by factors besides tk- 1 activity, including competition with endogenous thymidine, transport via nucleoside transporters, the degradative metabolism of phosphorylated metabolites, and the rate of DNA repair (37). Additionally, changes in perfusion rate, vascular permeability, and the activity of nucleoside transporters may alter ${ }^{18} \mathrm{~F}-\mathrm{FLT}$ uptake independently of cell proliferation (31).

Using PET/CT and PET/MR imaging, we identified soft tissues around the subtalar joints (and not the bone) as the locus of enhanced ${ }^{18} \mathrm{~F}$-FLT uptake in the inflamed ankles. MR imaging is used to assess the impact of GPI-induced arthritis on soft tissues, whereas CT cannot reveal erosions of the cortical bone at the site of the tendon insertion and strong reactive periosteal bone formation in acute experimental arthritis. Thus, for our RA model of acute arthritis, in which erosions of the cortical bone, the earliest phase of bone destruction, cannot be identified by PET/CT and histopathology, PET/MR imaging is a preferable method. However, for models of chronic experimental arthritis associated with severe bone destruction, PET/CT is a more promising method.

Contrary to our observations on ${ }^{18} \mathrm{~F}$-FLT uptake in inflamed ankles, van Waarde et al. observed no significant differences in tracer uptake between inflamed muscle tissues and healthy muscle tissues in an experimental model of sterile turpentine-induced inflammation (30). In these studies, PET was exclusively performed $24 \mathrm{~h}$ after turpentine injection, an early time point when the turpentine oil is surrounded by acute inflamed and partially necrotic muscle fibers as well as numerous neutrophils. Thus, the lack of observed ${ }^{18} \mathrm{~F}$-FLT uptake in inflamed muscle tissues could be due to the choice of an early analysis time point and the presence of partially necrotic muscle tissues. Moreover, the authors investigated rats and attributed the low ${ }^{18}$ F-FLT uptake to a high level of endogenous thymidine in the rodent serum. Therefore, the ${ }^{18} \mathrm{~F}$-FLT uptake may be strongly affected by the endogenous thymidine pool, which competes with ${ }^{18} \mathrm{~F}-\mathrm{FLT}$ for the 
binding site of nucleoside carriers in cell membranes and thus for the active site of the trapping enzyme, tk-1 (30).

In addition to studies of ${ }^{18} \mathrm{~F}$-FLT, several preclinical and clinical PET studies have been performed using ${ }^{18} \mathrm{~F}-\mathrm{FDG}$ and ${ }^{11} \mathrm{C}-(R)-[1-(2-$ chlorophenyl)- $N$-methyl- $N$-(1-methylpropyl)-3-isoquinolinecarboxamide] $\left({ }^{11} \mathrm{C}-(R)-\mathrm{PK} 11195\right)$ to investigate the extent of RA progression $(12,18,19,38,39)$. ${ }^{18} \mathrm{~F}$-FLT targets cell proliferation and ${ }^{18} \mathrm{~F}$-FDG glucose metabolism of resident and infiltrating leukocytes, whereas ${ }^{11} \mathrm{C}-(R)-\mathrm{PK} 11195$ targets peripheral benzodiazepine receptors that are mainly expressed in macrophages and monocytes and not in resident cells $(12,19,38)$. Despite the different targets of these tracers, the ${ }^{18} \mathrm{~F}-\mathrm{FDG}$ uptake in arthritic ankles is comparable to the ${ }^{11} \mathrm{C}-(R)-\mathrm{PK} 11195$ uptake $(18,39)$. In contrast to ${ }^{11} \mathrm{C}-(R)-\mathrm{PK} 11195,{ }^{18} \mathrm{~F}-\mathrm{FLT}$ and ${ }^{18} \mathrm{~F}-\mathrm{FDG}$ are not specific for detecting inflammation $(12,18,39)$. Comparative studies will show whether enhanced cell proliferation ( ${ }^{18} \mathrm{~F}$-FLT PET) in arthritic ankles is evident before enhanced glucose metabolism $\left({ }^{18} \mathrm{~F}-\mathrm{FDG}\right.$ PET). In addition, ${ }^{18}$ F-FLT PET/MR imaging could be helpful for evaluating the extent of arthritis and, in uncertain cases, for ensuring early diagnosis and treatment of RA; several clinical studies have shown that a short duration of symptoms before antiinflammatory treatment is a basic requirement for long-term drug-free remission of RA. In this context, ${ }^{18}$ F-FLT PET might be a superior diagnostic tool compared with power Doppler ultrasonography or MR imaging, especially for whole-body diagnosis of RA. Thus, the detection of subclinical arthritis by ${ }^{18}$ F-FLT PET/MR imaging may show promise for early detection of RA and hence early treatment of RA, especially in patients for whom the classification criteria of RA are only partially fulfilled-for example, patients who are positive for rheumatoid factor or anti-cyclic citrullinated peptide but in whom only 1-3 involved joints can be classified by clinical examination, radiography, ultrasonography, or MR imaging. Finally, comparative preclinical and clinical studies should be conducted to identify the potential of ${ }^{18} \mathrm{~F}$-FLT.

Because ${ }^{18}$ F-FLT PET is frequently used in the pharmaceutical industry and by academic researchers to determine the response of anticancer drugs (29,40-42), our imaging method may represent a useful tool for evaluating the impact of new therapeutics on cell proliferation both in experimental arthritis models and in humans. Additionally, PET/MR imaging and PET/CT are noninvasive techniques that enable longitudinal studies, allowing the investigation of a single subject at several time points. This feature may help reduce the number of laboratory animals required to evaluate new antiinflammatory agents. Moreover, for therapeutic studies, the same animals can be imaged both at baseline and during various treatment conditions over time.

\section{CONCLUSION}

Our data suggest that noninvasive in vivo detection of cell proliferation by ${ }^{18} \mathrm{~F}$-FLT PET could potentially be useful for the early detection of experimental arthritis before the onset of pannus formation and joint destruction. Early identification of pathologic changes such as enhanced cell proliferation with ${ }^{18} \mathrm{~F}$-FLT PET might be useful to investigate the extent of arthritic joint inflammation and other autoimmune diseases early in their course, before irreversible damage has occurred.

\section{DISCLOSURE}

The costs of publication of this article were defrayed in part by the payment of page charges. Therefore, and solely to indicate this fact, this article is hereby marked "advertisement" in accordance with 18 USC section 1734. This work was supported by the German Federal Ministry of Education and Research (BMBF, 0314103) and the Werner SiemensFoundation. No other potential conflict of interest relevant to this article was reported.

\section{ACKNOWLEDGMENTS}

We thank Mareike Lehnhoff, Daniel Bukala, Maren Koenig, Dennis Thiele, and Funda Cay for their excellent technical and practical assistance.

\section{REFERENCES}

1. Harris ED Jr. Rheumatoid arthritis: pathophysiology and implications for therapy. N Engl J Med. 1990;322:1277-1289.

2. Lee DM, Weinblatt ME. Rheumatoid arthritis. Lancet. 2001;358:903-911.

3. Firestein GS. Immunologic mechanisms in the pathogenesis of rheumatoid arthritis. J Clin Rheumatol. 2005;11(suppl):S39-S44.

4. Kneilling M, Hultner L, Pichler BJ, et al. Targeted mast cell silencing protects against joint destruction and angiogenesis in experimental arthritis in mice. Arthritis Rheum. 2007;56:1806-1816.

5. Cohen S, Hurd E, Cush J, et al. Treatment of rheumatoid arthritis with anakinra, a recombinant human interleukin-1 receptor antagonist, in combination with methotrexate: results of a twenty-four-week, multicenter, randomized, doubleblind, placebo-controlled trial. Arthritis Rheum. 2002;46:614-624.

6. Lipsky PE, van der Heijde DM, St Clair EW, et al. Infliximab and methotrexate in the treatment of rheumatoid arthritis. Anti-Tumor Necrosis Factor Trial in Rheumatoid Arthritis with Concomitant Therapy Study Group. $N$ Engl J Med. 2000;343:1594-1602.

7. van den Broek M, Huizinga TW, Dijkmans BA, Allaart CF. Drug-free remission: is it already possible? Curr Opin Rheumatol. 2011;23:266-272.

8. Nowosinska E, Avril S, Murray I, Szyszko T, Avril N. FDG-PET/CT as a molecular biomarker in ovarian cancer. Cancer Biomark. 2010;8:167-175.

9. Avril N. Metabolic FDG-PET imaging in breast cancer: implications for treatment stratification. Nat Clin Pract Oncol. 2007;4:336-337.

10. Gompels LL, Paleolog EM. A window on disease pathogenesis and potential therapeutic strategies: molecular imaging for arthritis. Arthritis Res Ther. 2011;13:201.

11. Hammer HB, Haavardsholm EA. Advances in imaging. Curr Opin Rheumatol. 2012;24:299-305.

12. Kubota K, Ito K, Morooka M, et al. FDG PET for rheumatoid arthritis: basic considerations and whole-body PET/CT. Ann N Y Acad Sci. 2011;1228:29-38.

13. Cheung PP, Dougados M, Gossec L. Reliability of ultrasonography to detect synovitis in rheumatoid arthritis: a systematic literature review of 35 studies (1,415 patients). Arthritis Care Res (Hoboken). 2010;62:323-334.

14. Reynolds A. Imaging rheumatic diseases. Radiol Technol. 2012;83:467-489.

15. Fueger BJ, Czernin J, Hildebrandt I, et al. Impact of animal handling on the results of ${ }^{18}$ F-FDG PET studies in mice. J Nucl Med. 2006;47:999-1006.

16. Hawkins RA, Choi Y, Huang SC, Messa C, Hoh CK, Phelps ME. Quantitating tumor glucose metabolism with FDG and PET. J Nucl Med. 1992;33:339-344.

17. Palmer WE, Rosenthal DI, Schoenberg OI, et al. Quantification of inflammation in the wrist with gadolinium-enhanced MR imaging and PET with 2-[F-18]fluoro-2-deoxy-D-glucose. Radiology. 1995;196:647-655.

18. Beckers C, Ribbens C, Andre B, et al. Assessment of disease activity in rheumatoid arthritis with ${ }^{18}$ F-FDG PET. J Nucl Med. 2004;45:956-964.

19. Irmler IM, Opfermann T, Gebhardt $P$, et al. In vivo molecular imaging of experimental joint inflammation by combined ${ }^{18} \mathrm{~F}-\mathrm{FDG}$ positron emission tomography and computed tomography. Arthritis Res Ther. 2010;12:R203. 
20. Yoshida S, Higuchi F, Ishibashi Y, et al. Downregulation of RCAS1 and upregulation of cytotoxic $\mathrm{T}$ cells affects synovial proliferation and apoptosis in rheumatoid arthritis. J Rheumatol. 2008;35:1716-1722.

21. Been LB, Suurmeijer AJ, Cobben DC, Jager PL, Hoekstra HJ, Elsinga PH. $\left[{ }^{18}\right.$ F]FLTPET in oncology: current status and opportunities. Eur J Nucl Med Mol Imaging. 2004;31:1659-1672.

22. Kenny L, Coombes RC, Vigushin DM, Al-Nahhas A, Shousha S, Aboagye EO. Imaging early changes in proliferation at 1 week post chemotherapy: a pilot study in breast cancer patients with $3^{\prime}$-deoxy- $3^{\prime}-\left[{ }^{18} \mathrm{~F}\right]$ fluorothymidine positron emission tomography. Eur J Nucl Med Mol Imaging. 2007;34:1339-1347.

23. Waldherr C, Mellinghoff IK, Tran C, et al. Monitoring antiproliferative responses to kinase inhibitor therapy in mice with $3^{\prime}$-deoxy- $3^{\prime}-{ }^{18} \mathrm{~F}$-fluorothymidine PET. J Nucl Med. 2005;46:114-120.

24. Pio BS, Park CK, Pietras R, et al. Usefulness of $3^{\prime}$-[F-18]fluoro- $3^{\prime}$-deoxythymidine with positron emission tomography in predicting breast cancer response to therapy. Mol Imaging Biol. 2006;8:36-42.

25. Paproski RJ, Ng AM, Yao SY, Graham K, Young JD, Cass CE. The role of human nucleoside transporters in uptake of $3^{\prime}$-deoxy-3'-fluorothymidine. $\mathrm{Mol}$ Pharmacol. 2008;74:1372-1380.

26. Dimitrakopoulou-Strauss A, Strauss LG. The role of ${ }^{18}$ F-FLT in cancer imaging: does it really reflect proliferation? Eur J Nucl Med Mol Imaging. 2008; 35:523-526.

27. Shields AF, Grierson JR, Dohmen BM, et al. Imaging proliferation in vivo with [F-18]FLT and positron emission tomography. Nat Med. 1998;4:1334-1336.

28. Krohn KA, Mankoff DA, Eary JF. Imaging cellular proliferation as a measure of response to therapy. J Clin Pharmacol. 2001;July(suppl):96S-103S.

29. Keen H, Pichler B, Kukuk D, et al. An evaluation of 2-deoxy-2-[ ${ }^{18}$ F $]$ fluoro-Dglucose and $3^{\prime}$-deoxy- $3^{\prime}-\left[{ }^{18} \mathrm{~F}\right]$-fluorothymidine uptake in human tumor xenograft models. Mol Imaging Biol. 2012;14:355-365.

30. van Waarde A, Jager PL, Ishiwata K, Dierckx RA, Elsinga PH. Comparison of sigma-ligands and metabolic PET tracers for differentiating tumor from inflammation. J Nucl Med. 2006;47:150-154.
31. Fuchs K, Kukuk D, Reischl G, et al. Oxygen breathing affects $3^{\prime}$-deoxy- $3^{\prime}-{ }^{18} \mathrm{~F}-$ fluorothymidine uptake in mouse models of arthritis and cancer. $\mathrm{J} \mathrm{Nucl} \mathrm{Med.}$ 2012;53:823-830.

32. Constantinescu CC, Mukherjee J. Performance evaluation of an Inveon PET preclinical scanner. Phys Med Biol. 2009;54:2885-2899.

33. Dardzinski BJ, Schmithorst VJ, Holland SK, et al. MR imaging of murine arthritis using ultrasmall superparamagnetic iron oxide particles. Magn Reson Imaging. 2001;19:1209-1216.

34. Kouskoff V, Korganow AS, Duchatelle V, Degott C, Benoist C, Mathis D. Organspecific disease provoked by systemic autoimmunity. Cell. 1996;87:811-822.

35. Korganow AS, Ji H, Mangialaio S, et al. From systemic T cell self-reactivity to organspecific autoimmune disease via immunoglobulins. Immunity. 1999;10:451-461.

36. Scholzen T, Gerdes J. The Ki-67 protein: from the known and the unknown. J Cell Physiol. 2000;182:311-322.

37. Brockenbrough JS, Souquet T, Morihara JK, et al. Tumor $3^{\prime}$-deoxy-3'-18 Ffluorothymidine $\left({ }^{18} \mathrm{~F}\right.$-FLT) uptake by PET correlates with thymidine kinase 1 expression: static and kinetic analysis of ${ }^{18}$ F-FLT PET studies in lung tumors. J Nucl Med. 2011;52:1181-1188.

38. Canat X, Guillaumont A, Bouaboula M, et al. Peripheral benzodiazepine receptor modulation with phagocyte differentiation. Biochem Pharmacol. 1993;46:551-554.

39. van der Laken CJ, Elzinga EH, Kropholler MA, et al. Noninvasive imaging of macrophages in rheumatoid synovitis using ${ }^{11} \mathrm{C}-(\mathrm{R})$-PK11195 and positron emission tomography. Arthritis Rheum. 2008;58:3350-3355.

40. Takeuchi S, Zhao S, Kuge Y, et al. ${ }^{18}$ F-fluorothymidine PET/CT as an early predictor of tumor response to treatment with cetuximab in human lung cancer xenografts. Oncol Rep. 2011;26:725-730.

41. Aide N, Kinross K, Cullinane C, et al. ${ }^{18}$ F-FLT PET as a surrogate marker of drug efficacy during mTOR inhibition by everolimus in a preclinical cisplatinresistant ovarian tumor model. J Nucl Med. 2010;51:1559-1564.

42. Yue J, Chen L, Cabrera AR, et al. Measuring tumor cell proliferation with ${ }^{18} \mathrm{~F}-$ FLT PET during radiotherapy of esophageal squamous cell carcinoma: a pilot clinical study. J Nucl Med. 2010;51:528-534. 